\title{
JUVENTUDE E \\ PERIFERIAS URBANAS: \\ PERFIL, CULTURA E OUTROS ASPECTOS DA \\ VIDA SOCIAL E AFETIVA
}

\author{
YOUTH AND URBAN PERIPHERIES: PROFILE, CULTURE AND OTHER ASPECTS \\ OF SOCIAL AND AFFECTIVE LIFE
}

JUVENTUD Y PERIFERIAS URBANAS:PERFIL, CULTURA Y OTROS ASPECTOS DE LA VIDA SOCIAL Y AFECTIVA

Adriana D'Agostini*

adridago@yahoo.com.br

\section{Gilberto Nogara Junior ${ }^{* *}$} gilrassico@gmail.com

\section{Luciana Pedrosa Marcassa ${ }^{* * *}$}

lumarcassa@gmail.com

REVISTA PEDAGÓGICA

Revista do Programa de Pós-graduação em Educação da Unochapecó | ISSN 1984-1566

Universidade Comunitária da Região de Chapecó | Chapecó-SC, Brasil Como referenciar este artigo: D'AGOSTINI A.; JUNIOR, G. N.; MARCASSA, L. P. Juventude e periferias urbanas: perfil, cultura e outros aspectos da vida social e afetiva. Revista Pedagógica, Chapecó, v. 19, n. 41, p. 137-153, maio./ago. DOI: http://dx.doi.org/10.22196/rp.v19i41.3785

RESUMO: Este texto tem por objetivo identificar e discutir a relação do jovem com a apropriação e produção da cultura e com outros aspectos da vida social e afetiva. Se a vida de uma maneira geral está submetida à lógica de produção e reprodução do capital, no que tange à juventude pobre das periferias urbanas de Florianópolis a situação é ainda mais delicada, tendo em vista as mediações próprias do território sobre a experiência da juventude, e que o trabalho e as preocupações em torno da qualificação para o emprego são o centro das atenções e tomam a maior parte do tempo e dos espaços de convivência desses jovens. A constituição de uma cultura de sobrevivência, portanto, é um elemento limitador das relações sociais e afetivas da juventude pobre e da produção criativa como modo de vida.

palavras-chave: Juventude. Cultura. Maciço do Morro da Cruz

ABSTRACT: This text aims to identify and discuss the relationship of a young person with theappropriation and production of culture and some other aspects of social and affectivelife. If life in general is the subject to the logic of production and reproduction ofcapital, with regard to the poor youth of the urban peripheries of Florianopolis thesituation is even more fragile. If we take the mediation of territory's view on theexperience of youth, and that the work qualification it is concerned as the central focusof the attention surrounding employment qualification alternatives and the spaces ofcoexistence of these youth. The formation of a survival culture, therefore, is the limitingelement of social and affective relations of the poor youth and of the creative productionas a way of life.

keywords: Youth,. Culture. Morro da Cruz Massif

RESUMEN: Este texto tiene como objetivo identificar y discutir la relación de los jóvenes con la producción y apropiación de cultura y otros aspectos de la vida social y afectiva. Si la vida en general está sujeta a la lógica de producción y reproducción del capital, con respecto a los jóvenes pobres de las periferias urbanas de Florianópolis, la situación es aún más delicada, teniendo en cuenta las mediaciones del territorio sobre la experiencia de la juventud, y que el trabajo y las preocupaciones alrededor de la capacitación para el trabajo son el centro de la atención y ocupan la mayor parte del tiempo y los espacios de convivencia de estos jóvenes. La configuración de una cultura de la sobrevivencia, por lo tanto, es un elemento limitante de las relaciones sociales y afectivas de la juventud pobre y de la producción creativa como una forma de vida.

Palabras clave: Juventud. Cultura. Maciço del Morro da la Cruz. 
* Doutora em Educação pela Universidade Federal da Bahia (UFBA). Docente do Departamento de Estudos Especializados em Educação e do Programa de Pós-Graduação em Educação do Centro de Ciências da Educação da Universidade Federal de Santa Catarina (PPGE/CED/UFSC).

\footnotetext{
** Mestre em Educação e Doutorando em Educação pelo Programa de Pós-Graduação em Educação do Centro de Ciências da Educação da Universidade Federal de Santa Catarina (PPGE/CED/UFSC).

*** Doutora em Educação pela Universidade Estadual de Campinas (UNICAMP). Docente do Departamento de Metodologia de Ensino e do Programa de Pós-Graduação em Educação do Centro de Ciências da Educação da Universidade Federal de Santa Catarina (PPGE/CED/UFSC).
}

\section{APRESENTAÇÃO}

Este artigo é resultado da análise de um dos eixos da pesquisa intitulada "Juventude Pobre e Escolarização: relações com a escola, o trabalho e a cultura em territórios de precariedade", que investigou as relações que a juventude pobre do maciço do Morro da Cruz, Florianópolis/SC estabelece com a escola, com o trabalho e com a cultura, considerando um conjunto de processos sociais que determinam a produção da existência em territórios de precariedade social. A pesquisa foi realizada em dez escolas de educação básica (identificadas aqui por números) localizadas no entorno desses territórios, tendo como sujeitos adolescentes e jovens estudantes dos anos finais do Ensino Fundamental e Ensino Médio, contabilizando 1.181 participantes da pesquisa.

O maciço do Morro da Cruz (MMC) está situado na porção central da cidade de Florianópolis, mas não integra o cenário paradisíaco da "Ilha da Magia", amplamente divulgado na mídia. Composto por aproximadamente 18 comunidades, sua população vive em assentamentos precários e ainda sofre pela ausência de investimentos públicos, pela falta de espaços de lazer e mesmo de serviços públicos adequados. De acordo com Dantas (2013), os dados levantados pela Prefeitura de Florianópolis indicam que a área total do maciço Central do Morro da Cruz é de 2,1 milhões de metros quadrados com uma população atual estimada em 22.708 moradores, distribuída entre 17 comunidades, sendo que 675 mil metros quadrados são de ocupação humana. Não há consenso, porém, em relação ao número de habitantes das comunidades dos morros, muito menos em relação ao número de comunidades existentes, já que algumas ocupações recentes ainda não foram devidamente catalogadas. Para as lideranças comunitárias do MMC, estima-se que existam, praticamente, 30.000 pessoas residindo nos morros, o que equivale a quase $8 \%$ da população absoluta da capital (DANTAS, 2013).

A ocupação destes morros da área insular de Florianópolis/SC iniciou-se, ainda, no final do século XIX por ocasião da política de sanitarização e embelezamento da cidade, que expulsou uma leva de homens e mulheres pobres dos passeios públicos e providenciou a demolição de cortiços, casas simples de pedreiros, marceneiros e de lavadeiras, para dar lugar a praças e prédios públicos, seguindo modelo da capital, à época, Rio de Janeiro (DANTAS, 2007). Foi na década de 1970, contudo, que Florianópolis vivenciou movimentos mais intensos de ocupação urbana e de especulação imobiliária antes não percebidos. São deste período as transformações no plano político e administrativo, bem como as práticas migratórias de populações originárias do campo e de outras regiões do estado de Santa Catarina. Essas grupos de migrantes, constituídos por migrações forçadas (oriundos primeiramente do interior do 
1 Os pioneiros saíram do Oeste e do Planalto de Santa Catarina. O crescimento da cidade trouxe mão de obra barata dessas regiões e também dos estados vizinhos. Mais recentemente, observou-se a chegada de contingentes significativos de migrantes oriundos do Norte e Nordeste e de outros países. Disponível em: <http://ndonline.com.br/ florianopolis/noticias/migracao-amplia-a-ocupacao-do-macico-do-morro-da-cruz-em-florianopolis> Acesso em: 26 nov. 2016. estado e atualmente do norte e nordeste do país) ${ }^{1}$, vieram a se instalar justamente nos morros e nas encostas do maciço central do Morro da Cruz, contribuindo para o crescimento da favelização, que resulta do processo de produção e intensificação das desigualdades sociais, articulado ao desenvolvimento do capitalismo no Brasil.

O alto dos morros da área central de Florianópolis viu sua ocupação multiplicar-se exponencialmente na última década, em virtude do aumento da migração de setores empobrecidos da população para a capital. O complexo de áreas do Morro da Cruz tem sido uma das alternativas encontradas pela população de baixa renda, como estratégia de viabilizar sua permanência na cidade. Não dispondo de recursos suficientes para entrar no setor habitacional regularizado, quer pela aquisição, construção ou aluguel, são obrigados a procurar áreas residuais do espaço urbano, com custo comparativamente baixo de acesso à terra, quer se trate de ocupação direta, ou aquisição de ocupantes anteriores. (PIMENTA; PIMENTA, 2011, p. 8).

Identificamos estes territórios, segundo David Harvey (2005), como espaços de "desenvolvimentos geográficos desiguais" ou, segundo Oliveira (2003), como resultado de um processo de "desenvolvimento desigual e combinado”. Logo, a ocupação do MMC não se caracteriza somente pela pobreza. O território de precariedade é cenário geopolítico de articulação entre o local e o global e faz parte do processo de desenvolvimento desigual e combinado do capitalismo contemporâneo que introduz e reproduz relações as mais avançadas e modernas, como também as mais arcaicas, todas necessárias e compatibilizadas à acumulação do capital. As contradições do desenvolvimento desigual e combinado neste território são evidentes e se expressam, por exemplo, pela convivência da pobreza com inúmeras construções de alto padrão e diversas empresas do setor das telecomunicações instaladas no ponto mais alto dos morros. Estas, por sua vez, contam com todos os recursos e serviços de infraestrutura, os mesmos que não são disponíveis aos habitantes. De acordo com o geógrafo David Harvey (2012):

No desenvolvimento mundial, a cidade está se dividindo em diferentes partes separadas, com aparente formação de muitos "microestados". Vizinhanças riquíssimas providas com todos os tipos de serviços, como escola exclusivas, campos de golfe, quadra de tênis e patrulhamento privado da área em torno; área de medidores entrelaçados com instalação ilegal onde a água é disponível apenas em fontes públicas, sem sistema de saneamento, a eletricidade é pirateada por poucos privilegiados, as estradas se tornam lamaçal sempre 
2 De acordo com Fontes (2010), as expropriações secundárias implicam a exaltação da disponibilidade dos trabalhadores para o mercado, o que impõe novas condições e abre novos setores para a extração de maisvalor. Um dos exemplos a considerar é a " [...] sistemática retirada do direito ao contrato de trabalho, ou a expropriação de direitos associados à atividade de produção de valor. Novas modalidades contratuais escassamente portadoras de direitos se generalizam, como subcontratações, terceirizações e, o mais impactante, trabalhadores vendendo força de trabalho desprovidos de qualquer contrato ou direito, por exemplo, através de bolsas de variados tipos ou de voluntariados organizados por grandes empresas" (FONTES, 2010, p. 60). que chove e onde as casas compartilhadas é a norma. (HARVEY, 2012, p. 81).

A análise de Harvey é referendada por estudos locais, tais como o realizado por Pimenta e Pimenta (2011). Segundo esses autores:

A falta de infra-estrutura [sic] urbana coloca sérios problemas para a higiene e a saúde da população local. Não existe rede pública de abastecimento de água nem de sistema de esgoto. A Prefeitura atual adotou como estratégia forçar a expulsão da população no que delimitou de Área de Preservação Permanente, conseguindo o impedir legalmente as concessionárias de serviços públicos de instalarem água e luz para os novos moradores. Assim, às carências provocadas pela precária inserção ou exclusão do sistema produtivo soma-se um empobrecimento adicional decorrente da impossibilidade de aceder aos serviços urbanos. A água da CASAN chega para a RBS (retransmissora regional da Rede Globo de televisão), mas não para as populações carentes apesar de estarem em cotas inferiores. Os moradores têm que improvisar canos de desvio da água da RBS, conhecidos por "gatos", que abastecem $77,42 \%$ da população entrevistada. Desta forma, confirma-se o fato de que $89,29 \%$ das casas não possuem medidor de água. Aqueles que nem mesmo podem ter acesso aos "gatos", devido, principalmente, à distância em relação às mangueiras, furam seus poços $(17,20 \%)$. Um sistema duplo poço e "gato" d'água ocorre em poucos casos, devido ao custo de perfuração, mas pode diminuir os prejuízos causados pelos cortes ocorridos no abastecimento irregular. A água corre intermitentemente e, não raras vezes, é cortada, quando existe ameaça de diminuição no fornecimento. (PIMENTA; PIMENTA, 2011, p. 10-11).

A pesquisa acima citada foi realizada em 2004. Atualmente, a situação referente à luz, água, esgoto e principais vias de acesso e circulação está em parte mais amenizada com as obras de urbanização do Programa de Aceleração do Crescimento (PAC). Ainda assim, este território encontra-se dominado pelo elevado poder destrutivo da lógica do capital, responsável pela desvalorização, autodestruição em diferentes escalas e lugares. No caso de Florianópolis, as melhorias observadas também correspondem aos interesses do setor imobiliário que, em conjunto com o Estado e sua inércia proposital, contribuem com o processo de expropriações secundárias $^{2}$ (FONTES, 2010), uma vez que o território do MMC tem uma posição privilegiada na cidade de Florianópolis.

Nesse contexto, objetivamos identificar e discutir a relação do jovem com a apropriação/produção da cultura 
e com outros aspectos da vida social e afetiva. Nossa hipótese é de que a vida e, em especial a vida dos jovens dos territórios de precariedade social, está subsumida à lógica de produção e reprodução do capital; portanto, trabalho e estudo ou outras formas de qualificação são o centro das atenções e tomam a maior parte do tempo e espaço de convivência, deixando pouco para as demais relações sociais e para a produção criativa como modo de vida.

As fontes da pesquisa são os questionários aplicados, grupos focais realizados e as entrevistas individuais que foram analisados e discutidos a partir do materialismo histórico dialético e das produções acadêmicas pertinentes à questão. O questionário continha 33 perguntas objetivas e foram tratadas pelo programa de estatística descritiva chamado de software MODALISA 7, Licence Educátion et Récherche. Os grupos focais e entrevistas foram realizados com estudantes dos $7^{\circ}$ e $8^{\circ}$ anos do Ensino Fundamental e $1^{\circ}, 2^{\circ}$ e $3^{\circ}$ anos do Ensino Médio das dez escolas pesquisadas.

Indicamos como temáticas que perpassam e estruturam deste artigo o debate sobre adolescência/juventude, o direito à cidade, a produção capitalista do espaço, a questão da participação social e política dos jovens, a religião, a produção cultural da juventude, a assimilação da indústria cultural, o uso das tecnologias como forma predominante de comunicação e interação, a produção da subjetividade e afetividade dos jovens a partir da relação com a família e com os amigos.

Assim, organizamos o artigo em duas seções. Primeiramente, apresentamos os marcos referenciais de um diálogo com o conceito e categoria "juventude", ao mesmo tempo em que procuramos traçar um perfil da juventude do MMC, alvo deste estudo. Posteriormente, abordaremos os temas da cultura, do direito à cidade e os demais aspectos da vida social e afetiva, que foram gerados pela pesquisa de campo.

\section{SOBRE JUVENTUDE E A CULTURA POSSÍVEL}

Juventude é uma categoria social que se caracteriza:

[...] ao mesmo tempo, pela heterogeneidade e pelo agrupamento, pela diversidade e pela semelhança, portanto, marcada por determinações de classe, gênero, etnia e também clivada por diferenças produzidas pelas condições educacionais e culturais, pelo local de moradia e pela relação que estabelece com outras gerações, em especial com o mundo adulto e sua entrada nele. Por isso, é importante compreender as experiências concretas nas quais a juventude se produz, articulando expectativas, o ambiente cultural, trajetórias, modos de pensar e agir com as condições materiais e concretas nas quais esses jovens estão inseridos. (MARCASSA, 2017, p. 14). 
Do ponto de vista do desenvolvimento da vida, segundo Vigotski (2000a, 200ob), a juventude se constitui em um processo dialético que se organiza em torno de uma unidade psíquica, física, mental, biológica e cultural. Esta unidade significa o amadurecimento das funções psicológicas relacionadas a três linhas de desenvolvimento, a saber: do desenvolvimento dos interesses, principalmente entre coetâneos; das funções psíquicas superiores; da imaginação e criatividade. De acordo com Foracchi (1972), são, ainda, características marcantes dessa fase da vida a rebeldia e a busca de independência/autonomia. Na juventude, as funções psicológicas superiores, que iniciaram seu desenvolvimento na infância, devem atingir a sua forma básica de desenvolvimento alcançando um funcionamento mediado, tipicamente humano.

O desenvolvimento dos interesses entre coetâneos se dá, inicialmente, pela negação dos pais/responsáveis na busca de uma independência maior, e, posteriormente, por uma divisão ou caracterização dos jovens com a criação de uma identidade visual e cultural bem definida. Algumas teorias chamam esses grupos de tribos, de galeras. $\mathrm{Na}$ pesquisa, foi possível identificar coletivos do rap, do funk, do hip-hop, do pagode, do skate, dos que pintam cabelos e barba coloridos. Cada um destes grupos tem um interesse, um estilo musical e uma corporeidade próprios, além da forma de vestir e das gírias. Segundo Eisenstadt et al. (1968), existem os grupos formais e informais. Nesta pesquisa, identificamos como grupos formais os que participam de grupos de jovens vinculados às igrejas, enquanto os demais são grupos informais. A participação em organizações sociais de maior complexidade, tanto culturais quanto políticas, não foi evidenciada para estes jovens.

Nestas ações e relações entre coetâneos, é possível identificar o potencial criativo e a imaginação desses jovens, principalmente pelas atividades que mais valorizam dentro da escola: a socialização, o convívio, as atividades que exigem trabalho em grupo e construção coletiva. O que eles dizem não gostar é a repetição monótona das lições, a cópia sem significado, as provas com base em memorização e avaliadas de forma meritocrática.

A juventude é uma constituição histórica a partir das necessidades e configurações das relações sociais com o mundo adulto e com as condições históricas de seu desenvolvimento a partir da organização e do modo de vida na sociedade moderna ocidental. Assim, de acordo com Foracchi (1972), para definir juventude como construção histórica e social é mister considerar as categorias idade, moratória, geração e crise de geração.

O contexto sociopolítico e econômico promoveram mudanças socioculturais que possibilitam maior liberdade e autonomia decorrentes da diminuição da autoridade e controle dos pais e da escola. O maior controle sobre os jovens agora está sob a tutela da realidade material de produção da vida, que acaba por limitar não só os jovens mas também toda a classe trabalhadora. 
Para determinado estrato social, classe média e alta, a sequência do ciclo de vida era mais clara até a década de 1970. O jovem, primeiramente, estudava; ao fim da escola, ele se empregava e, somente depois, casava. Hoje, no entanto, ocorre um processo de alongamento dessas fases para as duas classes fundamentais, porém com consequências mais graves para os jovens trabalhadores, pois este alargamento da juventude (15-29 anos) está associado a dificuldades cada vez maiores de obtenção de emprego e ao prolongamento do estudo. A falta de autonomia financeira e o desemprego contribuem para que os jovens permaneçam mais tempo com seus pais, conceito este conhecido como moratória, consequentemente ampliando as crises de gerações e os demais conflitos.

Os jovens da pesquisa, em sua maioria $(60,5 \%)$, encontram-se em uma faixa etária entre 15 e 17 anos, já 18,5\% são menores de 15 anos e $21 \%$ contabilizam jovens entre 18 e 29 anos. Como a pesquisa foi realizada em dez escolas de Educação Básica, 20\% correspondem aos estudantes do Ensino Fundamental e 80\% do Ensino Médio. Devemos considerar, contudo, que há estudantes na faixa etária de 15 a 17 anos que frequentam ainda o Ensino Fundamental e estudantes entre 18 e 29 anos que ainda frequentam o Ensino Médio, demonstrando que há defasagem entre idade e série entre os pesquisados.

A diferença entre meninos e meninas é pouco significativa, apenas de 5\%. Nesta questão, ficou evidente a existência de um debate sobre preconceito e questões de gênero. Os jovens que têm outra orientação sexual não responderam a esta questão e manifestaram a necessidade de serem reconhecidos. Um dos entrevistados aponta que tem namorado e que sua relação inclusive com a família é tranquila, mas não é assim com todo mundo. Em seu depoimento, ele diz: "eu tenho namorado". E sobre a relação com a família, ele responde: "São 'de boa'. Foi o primeiro que eu levei. Foram tudo 'de boa'. Eles aceitaram, não falaram nada. Ele dorme lá em casa, tudo assim” (Entrevista 1, ESCOLA 2, $8^{\circ}$ ano matutino, 2014).

Quanto às questões étnicas, os dados demonstram que $49,8 \%$ se declaram branco e $41,2 \%$ não branco (com uma variedade grande entre as demais autodeclarações: negro, mulato, mestiço, indígena). O interessante foi perceber as indagações e colocações de aproximadamente $9 \%$ dos jovens sobre esta questão no momento da realização dos questionários, apontando que sua raça é a "humana", que não há necessidade deste tipo de classificação; portanto, são contrários ao preconceito e ao racismo.

Os jovens de nossa pesquisa são pobres e a renda familiar se concentra em dois salários mínimos para $21,8 \%$, e de dois a quatro salários mínimos para 20,3\%. A maioria dos jovens - ou seja, $81,4 \%$ - não recebe ou não sabe se a família participa de algum Programa Social do Governo. Entre os que participam, 13,5\% recebem o Bolsa Família, 4,0\% estão vinculados ao Programa Jovem Aprendiz, o,6\% 
recebem o Bolsa Família e são Jovens Aprendizes e o,6\% recebem outros benefícios.

Em consequência da baixa renda familiar, os jovens moram na mesma casa, às vezes muito precária, com várias pessoas, e demonstram ter um conceito aberto e alargado de família. As configurações familiares foram muitas e não nos permitem demonstrá-las por gráfico ou quadro; mas, para exemplificar a complexidade desta questão, as formações de maior incidência são viver com os pais $66,0 \%$, somente com a mãe $11,8 \%$, com outros familiares avós, avôs, tios e tias, padrastos e madrastas - 8,0\%, com namorado(a)/esposo(a) 5,2\%, irmãos $1,7 \%$, com o pai $1,7 \%$. Nesta pesquisa ainda percebemos que, em geral, as mães são as responsáveis pelos filhos.

Não é de se estranhar que, ao serem questionados sobre com quem e onde se sentem mais felizes, as respostas foram "com minha família" $53 \%$ e "em casa" $51,8 \%$. Depois, aparecem os amigos com 18,3\% e a escola com 9,6\%.

A condição socioeconômica dos jovens pobres, que vivem nos territórios de precariedade social, faz com que eles se submetam à exploração do trabalho simples e desvalorizado bastante cedo: $28,3 \%$ dos jovens começaram a trabalhar entre os 12 e os 16 anos, $16,3 \%$ tiveram sua inserção no mundo do trabalho depois dos 16 anos e 2,1\% iniciaram atividade laborativa entre os 10 e 12 anos. Quando questionados sobre sua situação de estudante, 35,4\% responderam que estudam e trabalham e 33,7\% estudam e pretendem/precisam trabalhar. Estas condições auxiliam a construção de uma cultura de sobrevivência.

\section{SOBRE O DIREITO À CIDADE}

Na sociedade capitalista, o conceito de direito social é analisado com base no ethos individualista, característica inerente ao liberalismo econômico e político. Portanto, o destino pessoal é responsabilidade do indivíduo, o fracasso e/ou êxito dependem do esforço individual, os problemas sociais figuram como problemas pessoais. Segundo Netto (2006), isso ocorre por uma redefinição do público e do privado a partir da organização social capitalista:

[...] o que se passa é que a incorporação do caráter público da questão social vem acompanhada de um esforço da aparência da natureza privada das suas manifestações individuais. Ocorre como que uma redefinição do público e do privado [...], que atende tanto à invasão de todas as instâncias sociais pela lógica monopólica quanto à conservação de âmbitos onde se movem vetores contabilizados à órbita individual - dando naquele circuito que promove a polarização da esfera social e da esfera íntima. Ou seja, as refrações da questão social são deslocadas para os espaços de responsabilidade dos sujeitos individuais que as experimentam. (NETTO, 2006, p. 36). 
A condição de classe dos jovens estudantes é um elemento decisivo sobre o direito à cidade, a começar pelo título de propriedade e acesso aos serviços básicos de infraestrutura existentes no maciço do Morro da Cruz. A necessidade de vender sua força de trabalho e estudar ao mesmo tempo - ou para poder continuar os estudos, o trabalho ser condição necessária - é um elemento determinante de condicionamento dos jovens às experiências culturais limitadas às regiões circundantes ao local de trabalho e de estudos. Não faltam passagens nos grupos focais onde esta questão é reafirmada:

Eu não tenho lazer. Eu trabalho e [vou] pro colégio. Trabalho a semana inteira. No final de semana, tem que estar faxinando a casa, comida para as crianças. A praia aqui é muito longe. Eu acho, né. Tem que pegar 3 , 2 ônibus para ir para a praia. Pra dar um lazer para as crianças, eu gasto muito mais. Entendesse? Se fosse todo final de semana dar um lazer para as crianças, tem que gastar bastante. A praia, para chegar à praia, 4, 3 horas mais ou menos. Só uma praia que conheci aqui. Quando é verão, é sempre aquela prainha, aquela prainha. Se eu for para outra, eu vou gastar mais. É porque são muito caras as coisas na praia, eu acho. (Grupo focal ESCOLA1o / EJA segundo segmento - matutino, 2015).

Sabe-se que a falta de espaços e equipamentos públicos de lazer, praças, parques, jardins ou mesmo áreas verdes é um dos aspectos notáveis dos territórios do maciço do Morro da Cruz em Florianópolis. Talvez por isso, na ausência de outros locais públicos, a escola tenha se configurado como espaço de lazer e o trabalho como lugar que possibilita ao jovem - ao mesmo tempo - realização pessoal, distração e alheamento dos problemas relativos à falta de espaços e oportunidades de lazer próximos à sua moradia. Nos grupos focais, esta realidade foi relatada: "Hoje eu vou sair de casa para poder descansar, pensar mais em mim, no meu futuro, que é o meu colégio. Então aqui [Núcleo EJA] é como se fosse, assim, uma área de lazer" (Grupo focal ESCOLA 10 / EJA, segundo segmento - matutino, 2015).

No segundo exemplo, um jovem que trabalha há seis meses e quatro horas por dia em um supermercado informa: "Eu gosto [de trabalhar aqui], porque eu me sinto mais feliz, eu me esqueço das coisas, que em casa não tenho nada para fazer" (Grupo focal ESCOLA 10 / EJA, segundo segmento - matutino, 2015).

Ao mesmo tempo em que a renda é um meio de os jovens terem mais independência em relação aos seus pais e familiares/responsáveis, a obtenção dessa renda por meio do trabalho é um fator limitante do usufruto da cidade e também da continuidade dos estudos: 
Eu trabalho até domingo. Eu trabalho todos os dias, só tenho uma folga na semana; então, não sobra muito tempo para descansar [...]. Eu queria ter mais tempo para me dedicar, fazer um pré-vestibular, que eu tive que desistir no começo do ano porque eu tive que trabalhar. Necessidade fala mais alto; dai eu mudei para a noite e ficou assim mesmo. Mas, ano que vem eu quero me dedicar. (Grupo focal ESCOLA 9, 3EM - noturno, 2015).

Trabalhar e estudar é complicado. É muita correria! Só fazer cursinho já é muito puxado. Ficam até as dez da noite na escola. Quanto mais trabalho, menos se dedica aos estudos. É difícil conciliar tudo! Eu penso em trabalhar este começo de ano para eu ter uma renda e começar a ser um pouco mais independente dos meus pais. (Grupo focal ESCOLA 6, 3EM - matutino, 2015).

Esta também é a realidade dos estudantes que fazem parte do Projeto Jovem Aprendiz: "Comecei [a trabalhar] com 15. Foi com o Jovem Aprendiz. Comecei com 14 (anos), e saí no ano passado [...]. No primeiro mês, fiquei cansadão. Tinha que vim pro colégio de manhã e ia pro banco de tarde. Chegava em casa à noite, e dormia cansado". (Grupo focal ESCOLA 5, 2EM - matutino, 2015).

De modo geral, a idade de inserção no trabalho via o referido programa se dá entre 14 e 15 anos, com jornada de trabalho de quatro horas, nos mais variados locais de trabalho, tais como: hospitais, órgãos públicos e principalmente em bancos, no auxílio a clientes, e em supermercados exercendo a função de empacotador ${ }^{2}$. Os jovens aprendizes em sua formação são orientados a:

[...] como tratar os clientes, sobre o que devem conversar no ambiente de trabalho, como devem se comportar, e por último, é exigido que sejam eficientes no que fazem, desempenhando suas atividades com o máximo de qualidade possível. (PESSOA et al., 2014, p. 26).

A questão comportamental-atitudinal combinada à ideia de oportunidade são elementos que despontam nas falas dos estudantes que estão no Programa Jovem Aprendiz: "Eu entrei como Jovem Aprendiz pela FUCAS e, assim, quem quer e quem se esforça bastante, eles dão bastante oportunidade. Eu trabalhei no ANGELONI, como auxiliar de caixa [...]".

O Jovem Aprendiz, na verdade, digamos que ele oportuniza uma vaga de emprego. A partir do momento que tu entra no curso, ele já tem uma vaga destinada pra ti em algum emprego, que é pra tu ter experiência nisso, 
no caso, ela foi no Angeloni, eu na EPAGRI. (Grupo focal ESCOLA 8, 3EM - matutino, 2014).

Os jovens que trabalham no Programa Jovem Aprendiz (PJA) exercem funções análogas a de qualquer trabalhador contratado dentro dos mesmos parâmetros mínimos estipulados pelas leis trabalhistas, ainda que sua carga horária seja reduzida e possa possibilitar, em alguns casos, o estudo no local de trabalho:

Eu sou aprendiz, trabalho quatro horas. Eu estudo de manhã, trabalho de tarde e faço cursinho de noite. Dá para associar bem. Lá é bem tranquilo; dá para estudar 'de boa'. Tem dias que eu não faço quase nada lá (Grupo focal ESCOLA 1, 3EM - matutino, 2014).

Eu trabalho quatro horas por dia também no hospital SOS Cárdio. Eu trabalho de menor aprendiz. Eu estudo de manhã e trabalho de tarde; então, eu tenho muito tempo livre. E, no meu trabalho, também consigo adiantar bastante parte da escola. Eu acho que não me atrapalha em nada. (Grupo focal ESCOLA 1, 3EM - matutino, 2014).

Em que pesem as impressões positivas e negativas trazidas pelos jovens em relação ao Programa Jovem Aprendiz, é importante compreendê-las no contexto de desemprego estrutural e de seu recrudescimento no último biênio que afeta de modo contundente os jovens. Por um lado, observa-se uma flexibilização maior das relações trabalhistas em favor das empresas que contratam jovens estudantes; por outro lado - diante do desemprego e da necessidade de trabalhar para poder estudar ou almejar a continuação dos estudos - o PJA surge como uma "oportunidade" indiscutível. O contexto de desemprego é utilizado pelos empresários como argumento para obtenção de vantagens fiscais e flexibilização do trabalho; por sua vez, os jovens, vivendo e sentindo a realidade deste mesmo contexto de desemprego, não podem abrir mão de qualquer chance de vender sua força de trabalho, uma vez que, conforme apontam os dados de nossa pesquisa, para estudar o estudante precisa trabalhar e para trabalhar o estudante precisa estudar.

Só que eu não consigo. Eu queria muito ter esse luxo de só viver para os estudos. Só que eu tenho outras coisas para fazer também. Lá em casa, nós somos em três irmãos. Todos trabalham e têm o seu dinheiro. Eu queria ter essa sorte de entrar em uma faculdade pública, para poder estudar sem ter um gasto maior; mas, pode ser que eu não consiga passar no vestibular da federal, por 
exemplo. E eu vou ter que pagar os meus estudos, vou ter que pagar uma privada e eu vou precisar desse dinheiro para isso. Por isso que eu tenho que dar um jeito de conciliar os dois. (Grupo focal ESCOLA 1, 3EM - noturno, 2014).

A continuação dos estudos é objetivo da maioria dos jovens pesquisados $(88,2 \%)$. No entanto, o prosseguimento da formação - inclusive no Ensino Médio - depende da inserção/manutenção destes jovens no mercado de trabalho, uma vez que, do percentual acima destacado, 56,5\% indicaram a necessidade de trabalhar para seguir estudando. De acordo com Foracchi (1977, p. 136):

[...] o estudante que trabalha não pode impedir que sua atividade esteja cindida entre o emprego e o estudo, na medida em que um é condição do outro. Com isso, a aprendizagem, assim como o emprego só podem ser parciais, tanto no que diz respeito ao aproveitamento quanto no que se relaciona com a experiência obtida, num ou noutro setor.

Tabela 1 - Continuidade dos estudos e expectativas de futuro profissional por áreas/setores de atuação.

\begin{tabular}{|c|c|c|c|c|c|}
\hline Escola & ESCOLA 5 & ESCOLA 3 & ESCOLA 8 & ESCOLA 6 & ESCOLA 10 \\
\hline & Administração & Gastronomia & Publicidade & Direito & Direito \\
\hline & $\begin{array}{l}\text { Atuar como jogador de } \\
\text { futebol }\end{array}$ & $\begin{array}{l}\text { Ciências } \\
\text { Contábeis }\end{array}$ & Educação Física & Administração & Veterinária \\
\hline & Concurso Público & Direito & Psicologia & Psicologia & Arquitetura \\
\hline & Veterinária & Letras & Fisioterapia & Educação Física & Designer \\
\hline & Medicina & Cinema & Economia & Programação & \\
\hline \multirow[t]{5}{*}{ Escola } & ESCOLA 2 & ESCOLA 9 & ESCOLA 1 & ESCOLA 4 & ESCOLA 7 \\
\hline & Atuar como Hacker & Educação Física & Engenharia & Farmácia & Medicina \\
\hline & Pediatria & Moda & Matemática & Jornalismo & Veterinária \\
\hline & Otorrinolaringologia & Medicina & Nutrição & $\begin{array}{l}\text { Atuar como } \\
\text { jogador de } \\
\text { futebol }\end{array}$ & $\begin{array}{l}\text { Ciências } \\
\text { Contábeis }\end{array}$ \\
\hline & $\begin{array}{c}\text { Gastronomia (atuar como } \\
\text { Chef de Cozinha) }\end{array}$ & Enfermagem & Arquitetura & & \\
\hline
\end{tabular}

Fonte: Elaborada pelos autores, com base nos dados coletados a partir dos grupos focais.

Nossa hipótese parte da constatação de que trabalho e estudo são o centro das atenções e tomam a maior parte do tempo de vida dos jovens, restando assim pouco tempo para outras formas de convívio social, conforme aponta uma jovem trabalhadora-estudante do Ensino Médio:

Olha eu sou bem sincera. Eu não tenho muita amiga para conviver, pra dizer assim: "vou passar o final de semana junto". Eu sou mais o meu cantinho. Às vezes, vou perturbar um pouco minha irmã no final de semana. Gosto de assistir um filme com ela, e faz um três anos que eu nã̃o sei o que é baile, sair com 
meu marido, assim sabe só nós dois. Então, assim... Minha vida é praticamente em função do trabalho, colégio agora, e as crianças. (Grupo focal ESCOLA 10 / EJA, segundo segmento - matutino, 2015).

A participação dos jovens em grupos fora da escola restringe-se às igrejas (14,7\%), associações ligadas ao futebol $(6,2 \%)$ e atividades ligadas a Organizações Não Governamentais (1\%). Participações ligadas aos movimentos sociais $(0,8 \%)$, movimentos culturais $(0,8 \%)$ e associações de moradores $(0,4 \%)$ também foram citadas, mas a frequência é muito baixa.

Um dos motivos apontados pelos jovens sobre a não participação em movimentos sociais ou em manifestações de cunho político é a repressão violenta. Quando perguntado sobre a participação em movimentos como o Passe-Livre, por exemplo, as respostas foram:

- Não, não. Isso aí não. Eu não saio de casa. Eu não me encarno. [...] Tipo... Não é passeata que se diz... Manifestação? Manifestação! Eu não me encarno.

- Isso aí sempre dá rolo no final, porrada.

- É uma loucura! (Grupo focal ESCOLA 5, 2EM - matutino, 2015).

Frente à constatação de que trabalho e estudos tomam a maior parte do tempo destes jovens, que a realidade do MMC é marcada pela pobreza, pela violência, pelo trabalho explorado, pela falta de infraestrutura nos bairros como, assistência à saúde, escolas, lazer, transporte, limpeza, fornecimento de água e energia, serviço de esgoto etc. (DANTAS; VENDRAMINI, 2012), o acesso à internet configura-se como um "refúgio seguro" utilizado dentro das casas e também como meio de obter informações, checar notícias, curiosidades e "buscar conhecimento através de videoaulas" (Grupo focal, ESCOLA 5 - 2EM matutino, 2015).

- Eu fico na internet e lavo a louça, quando estou em casa. Porque eu fico na jornada ampliada todo dia até as 6 horas.

- Quando eu to em casa, eu limpo a casa, entro na internet e durmo. (Grupo focal ESCOLA 7, 8EF - matutino, 2015).

Contudo, os jovens estudantes das escolas pesquisadas identificam o problema para além dos aspectos individuais, em outras palavras, sinalizam a exploração e a acumulação de riqueza por parte da sociedade como causadores da pobreza, conforme aponta um estudante do Ensino Médio:

Por exemplo, 50\% da riqueza do Brasil está nas mãos de $1 \%$ da população brasileira. 
Quantas pessoas estão trabalhando duro $e$ outras somente gastando. Eu não digo que tem que ser todo mundo igual, dividido igual, mas com uma diversificação maior. (Grupo focal ESCOLA 6, 3 EM - matutino, 2015).

As dificuldades de toda ordem enfrentadas pelos estudantes, somadas à constatação de sua condição de explorado, resultam em uma expectativa - em relação à sociedade de modo geral - marcada pela imobilidade:

Vai ser difícil mudar o jeito que nós fomos educados. O jeito que o Brasil foi descoberto foi mandado pessoas para cá, para ocupar terras. Acho que isso prejudicou bastante, porque tem muito poder na mão de poucas pessoas, e isso eleva as dificuldades, porque aqueles que têm sempre querem mais, exploram mais os que não tem. (Grupo focal ESCOLA 6, 3 EM - matutino, 2015).

A questão sobre as expectativas dos jovens em relação ao futuro da sociedade pode ser abordada segundo um duplo viés. Nos questionários - analisando as respostas individualizadas - observa-se que $38 \%$ dos jovens acreditam que "haverá mudanças para melhor", o que de certa maneira contrastaria com a assertiva ceticista presente no dado referente ao grupo focal. Para $21 \%$ dos jovens, "só vai piorar daqui para a frente", enquanto para 10,6\%, "tudo ficará como está" e, por fim, 30,2\% "não sabem" o que responder em relação ao futuro da sociedade. Mas também podemos analisar as respostas em blocos; desse modo, para $31,6 \%$ dos jovens estudantes o futuro da sociedade "ficará igual ou pior do que está". O fato de os estudantes não saberem o que responder é um indicativo de dúvidas e incertezas em relação ao futuro da sociedade. Portanto, levando em consideração a análise das questões em bloco, $61,8 \%$ dos estudantes têm incertezas ou acreditam que o futuro da sociedade será igual ou pior do que o que vivemos.

\section{CONSIDERAÇÕES FINAIS}

Os jovens vão construindo suas possibilidades de se inserir na sociedade adulta, em termos cognitivos, afetivos, de capacidade de trabalho e de reprodução, o que fica evidente nos depoimentos sobre o que é ser jovem. A maioria dos participantes da pesquisa considerou que a juventude precisa assumir responsabilidades com as coisas em geral e com a sua vida, tendo como parâmetro de comparação a despreocupação da infância.

A rebeldia, a moratória, a geração, a instabilidade, a busca de identidade e os conflitos são características próprias desta fase da vida e estes conceitos têm demonstrado validade e atualidade para o tratamento da questão, uma 
vez que encontram respaldo na realidade observada, que é o critério de verdade segundo o materialismo histórico dialético. No caso dos jovens da pesquisa, ficou claro que a relação entre renda, moradia e constituição familiar são condições objetivas de vida que explicam a moratória, ou seja, o prolongamento do tempo de permanência dos jovens na casa dos pais/familiares.

Em relação ao direito à cidade, são restritas as possibilidades de interação social e de trabalho ontocriativo (MARX, 2006) devido às limitações dos espaços públicos e da vivência do tempo livre (para além dos estudos e do trabalho) em nossas cidades. A falta de praças, parques, quadras, palcos etc. somada à violência generalizada e a predominância do lazer como entretenimento e consumo, contribuem para reduzir a convivência e as relações sociais e afetivas dos jovens às suas casas e à escola, com suas famílias e seus grupos pequenos de amigos e professores. Assim, a pesquisa quebra alguns mitos no tocante à relação dos jovens com a família e com a escola. Por exemplo, no que diz respeito ao discurso oficial que culpabiliza o fracasso social e escolar, e acusa as famílias de serem instáveis e desestruturadas, os jovens admitem uma diversidade de conceitos de família e parecem incorporar uma noção de família alargada, convivendo bem com sua configuração familiar. Os jovens consideram a família fundamental em suas vidas, tanto que, ao refletir sobre onde e com quem se sentem mais felizes, "em casa" e "com a família" foram as principais respostas. Já a escola ganha lugar de destaque na formação moral e ético-normativa dos jovens, pois é vista como possibilidade de ampliação das relações sociais, tanto presenciais, nos momentos em que se está na escola, quanto virtualmente, comunicando-se de casa com os colegas da escola por meio das redes sociais.

Os jovens produzem uma cultura própria a partir de seu modo de vida, o que é perceptível em suas atitudes, na forma como se vestem, nas músicas, danças, estratégias e nos veículos de comunicação. A comunicação virtual se mostrou muito significativa na pesquisa, evidenciando que a falta de espaços de socialização e a falta de segurança têm sido contornadas, para o bem ou para o mal, pela tecnologia, principalmente pela internet. Mas estas formas precisam ser compreendidas na sua ambiguidade, como comunicação e modo de estar com seus coetâneos, fenômeno característico dos jovens que reinventam as possibilidades diante das necessidades e dos limites postos pela sociedade atual, ao mesmo tempo em que são veículos de internalização da ideologia dominante (MÉSZÀROS, 2005).

Assim, a pesquisa revela que o trabalho e o estudo tomam ou ocupam a maior parte do tempo de vida e do espaço de circulação dos jovens, restando pouco mais do que a apropriação cultural daquilo que é disponibilizado pela indústria cultural e de consumo, por exemplo, seguir os famosinhos e pop stars nas redes sociais e jogos eletrônicos. Portanto, a vivência da juventude para parte significativa 
da classe trabalhadora, que se constitui em uma cultura de sobrevivência, implica um salto da infância à fase adulta mediada por uma formação escolar e cultural para o trabalho simples e pela inserção precoce e precária no mercado de trabalho.

Finalmente, concluímos que a necessidade de incremento da renda familiar (que mantém o jovem vinculado ao ambiente doméstico), a falta de tempo livre para compartilhar situações próprias da juventude com seus coetâneos e a ausência de espaços públicos de convívio para além do ambiente doméstico produzem uma cultura de sobrevivência que restringe outras possibilidades de produção cultural e construção de outras relações sociais e, portanto, também os horizontes de formação e realização de projetos futuros, capazes de abrir caminhos para a emancipação humana.

\section{REFERÊNCIAS}

DANTAS, Jéferson S. Projeto histórico e construção curricular: a experiência social do Fórum do Maciço do Morro da Cruz. Revista Brasileira de Estudos Pedagógicos, Brasília, v. 88, n. 218, p. 122-139, jan./abr. 2007.

DANTAS, Jéferson S.; VENDRAMINI, Célia R. Contradições em torno da relação do Fórum do Maciço do Morro da Cruz com o Terceiro Setor: desafios políticos e pedagógicos. (2012). Revista Pedagógica, Chapecó, ano 16, v. 2, n. 29, p. 37-74, jul./dez. 2012.

DANTAS, Jéferson S. Reescrever o mundo com lápis e não com armas: a experiência política e pedagógica da Comissão de Educação do Fórum do Maciço do Morro da Cruz em Florianópolis (SC). Florianópolis: Em Debate, 2013.

EISENSTADT, Shmuel. Noah. Grupos informais e organizações juvenis nas sociedades modernas. In: BRITTO, Sulamita. (Org.). Sociologia da Juventude IV: os movimentos juvenis. Rio de Janeiro: Zahar Editores,1968. p. 13-30.

FONTES, Virgínia. O Brasil e o capital-imperialismo: teoria e história. 2. ed. Rio de Janeiro: EPSJV/Editora UFRJ, 2010.

FORACCHI, Marialice Mencarini. A juventude na sociedade moderna. São Paulo: Pioneira, 1972.

FORACCHI, Marialice Mencarini. O estudante e a transformação da sociedade brasileira. São Paulo: Companhia Editorial Nacional, 1977.

HARVEY, David. A produção capitalista do espaço. São Paulo: Anna Blume, 2005. 
HARVEY, David. O direito à cidade. 2012. Disponível em: <http://www4.pucsp.br/neils/downloads/neilsrevista-29-port/david-harvey.pdf>. Acesso em: 5 fev. 2017.

MARCASSA, Luciana Pedrosa. (Coord.). Relatório de Pesquisa. Juventude pobre e escolarização: relações com a escola o trabalho e a cultura em territórios de precariedade. Departamento de Metodologia de Ensino, Centro de Ciências da Educação, Universidade Federal de Santa Catarina, maio de 2017. (mimeo).

MARX, Karl. O Dezoito Brumário de Louis Bonaparte. São Paulo: Centauro, 2006.

MÉSZÀROS, Ístvan. Educação para além do capital. São Paulo: Boitempo, 2005.

NETTO, José Paulo. As condições histórico-sociais da emergência do serviço social. In: NETTO, José Paulo. Capitalismo monopolista e serviço social. São Paulo: Cortez, 2006. p. 15-51.

OLIVEIRA, Francisco. Crítica à razão dualista: 0 ornitorrinco. São Paulo: Boitempo, 2003.

PESSOA, Manuella Castelo Branco; ALBERTO, Maria de Fátima Pereira; MÁXIMO, Thaís Augusta Cunha de Oliveira; SOUZA Paulo César Zambroni de. Formação profissional de jovens: a que se destina? Estudos de Psicologia, Natal, v.19, n.1, p. 22-30, jan/mar. 2014. Disponível em: <http:// www.scielo.br/scielo. ${ }^{\text {php}}$ ? script $=$ sci_arttext\&pid $=$ S1413294X2014000100004>. Acesso em 10 mar. 2017.

PIMENTA, Margareth de Castro Afech; PIMENTA, Luís Fugazzola. Pobreza e qualidade de vida nos morros centrais de Florianópolis: a escalada de um distanciamento. ACTA Geográfica, Boa Vista, v. 5, n. 9, p.47-66, jan./jun. 2011.

ROSA, Edson. Migração amplia a ocupação do maciço do Morro da cruz, em Florianópolis. 2 jan. 2014. Notícias do Dia. Disponível em: <https://ndonline.com.br/ florianopolis/noticias/migracao-amplia-a-ocupacao-domacico-do-morro-da-cruz-em-florianopolis $>$. Acesso em: 5 fev. 2017.

VYGOTSKY, Lev Semenovitch (1930). Teoria e método em psicologia. 3. ed. São Paulo: Martins Fontes, 2000 .

VYGOTSKY, Lev Semenovitch. A Construção do Pensamento e da Linguagem. São Paulo: Martins Fontes, 200ob. 